\title{
ÉDOUARD GLISSANT, FRANÇOIS NOUDELMANN, L'entretien du monde
}

\section{Carminella Biondi}

\section{(2) OpenEdition}

\section{Journals}

\section{Édition électronique}

URL : http://journals.openedition.org/studifrancesi/15961

DOI : 10.4000/studifrancesi. 15961

ISSN : 2427-5856

\section{Éditeur}

Rosenberg \& Sellier

\section{Édition imprimée}

Date de publication : 1 décembre 2018

Pagination : $543-544$

ISSN : 0039-2944

\section{Référence électronique}

Carminella Biondi, «Édouard glissant, françois noudelmann, L'entretien du monde », Studi Francesi [En ligne], 186 (LXII | III) | 2018, mis en ligne le 01 janvier 2019, consulté le 06 janvier 2021. URL : http:// journals.openedition.org/studifrancesi/15961 ; DOI : https://doi.org/10.4000/studifrancesi.15961

Ce document a été généré automatiquement le 6 janvier 2021.

\section{(C) $\odot \Theta$}

Studi Francesi è distribuita con Licenza Creative Commons Attribuzione - Non commerciale - Non opere derivate 4.0 Internazionale. 


\title{
ÉDOUARD GLISSANT, FRANÇOIS NOUDELMANN, L'entretien du monde
}

\author{
Carminella Biondi
}

\section{RÉFÉRENCE}

ÉDOUARD GLISSANT, FRANÇOIS NOUDELMANN, L'entretien du monde, Presses Universitaires de Vincennes, 2018, $203 \mathrm{pp}$.

1 Le philosophe François Noudelmann, qui vient de publier, chez Flammarion, une importante (et contestée) biographie d'Édouard Glissant (Édouard Glissant. L'identité généreuse), réunit, sous ce suggestif titre glissantien, six entretiens qu'il a eus avec l'auteur entre 2002 et 2009, auxquels il ajoute sept articles, publiés presque tous sur revue, entre 2004 et 2014. Il s'agit d'un ensemble qui pourrait paraître incongru, vu la nature différente des objets réunis, mais qui se révèle, par contre, très fonctionnel à la connaissance du «dernier Glissant». En effet, les entretiens, très solidement structurés, avec parfois des «violences» de la part de l'intervieweur, pour pousser l'auteur dans ses retranchements, laissent entrevoir les mécanismes d'une pensée in fieri, qui se cherche, qui se corrige, qui sort avec fatigue ou habileté d'une impasse, qui s'interroge... Une pensée vivante et passionnée, toujours en prise sur le monde dont Glissant cherche à saisir et à dire la polyphonie. Ces entretiens concernent les concepts clés de la pensée glissantienne: la relation, la créolisation, la pensée archipélique, la pensée du toutmonde, l'utopie dans un monde dominé par l'imprévisible, mais aussi l'esthétique, où se révèle le rôle important joué par la beauté pour Glissant et donc le lien étroit entre esthétique et philosophie, entre poésie et philosophie. Il y a enfin Les entretiens sur la politiques, de 2008 (pp. 90-120), ou l'intervieweur «contraint» Glissant à confronter sa pensée avec la réalité politique: c'est peut-être l'entretien qui demande le plus grand effort de la part de l'auteur, mais dont les résultats sont du plus grand intérêt pour nous, et d'une extrême actualité, car s'y confrontent deux mentalités, deux visions du réel: la vision occidentale de l'intervieweur et la vision ouverte sur le monde de 
l'interviewé, qui affirme: «dans le monde il n'y a plus de droite et de gauche. Ça n'existe plus. C'est en Europe qu'il y a encore des combats de droite et de gauche» (p. 100). Et encore plus inquiétant et plus prophétique, ce qu'il dit à propos de la démocratie, que l'Occident prétend exporter: «La démocratie n'est pas un système stable [...]. L'entrée en démocratie est toujours un accident. Ce n'est pas une naturalité. Et de même la sortie de la démocratie est toujours un accident. [...] tu ne peux pas, à mon avis, proposer un modèle démocratique valable partout et pour tous. Il y a des moments antidémocratiques qu'il faut combattre par des moyens non démocratiques» (pp. 104-106). Un ensemble de questions et de réponses à lire attentivement et à méditer, car elles n'ont pas seulement la fonction de nous aider à mieux connaître le laboratoire de la pensée glissantienne, mais aussi de nous contraindre à réfléchie sur les grands défis de notre temps.

Les essais qui suivent, sont complémentaires aux entretiens; ils focalisent l'attention du lecteur sur des thèmes précis, connus et moins connus, tels que filiation, créolisation, pensée archipélique, trame et tourbillon, mémoires, Traite et Shoah, transmission du savoir sans tomber dans le piège de l'universel, etc. Dans leur ensemble, ces essais analysent et synthétisent, de manière éclairante la pensée de Glissant, avec parfois une participation poétique et émue, très saisissante, comme dans la conclusion de l'article Mémoire d'Édouard Glissant (publié d'abord dans le numéro 63 de la revue "Francofonia», en 2013): «La mémoire des traversées est présente au cœur de cette méditation, avec l'étendue bleue striée par les vagues en arrière-plan. La parole se déploie sur ce fond indicible et ces cris noyés, elle produit des figures de pensée pour décrire le monde qui vient, sa créolisation, son imprévisibilité et sa transformation. Elle incarne le passage $\mathrm{du}$ temps et sa transmission dans l'écume d'une mémoire labile qui trompe naturellement ses destins» (p. 180). C'est la voix de Noudelmann, qui semble se mettre au diapason de la voix de Glissant. 